\title{
Article \\ Curdlan-Based Hydrogels for Potential Application as Dressings for Promotion of Skin Wound Healing-Preliminary In Vitro Studies
}

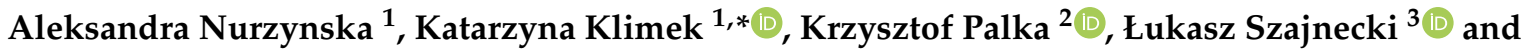 \\ Grazyna Ginalska ${ }^{1}$ (D) \\ 1 Department of Biochemistry and Biotechnology, Medical University of Lublin, Chodzki 1 Street, \\ 20-093 Lublin, Poland; aleksandra.nurzynska@umlub.pl (A.N.); g.ginalska@umlub.pl (G.G.) \\ 2 Faculty of Mechanical Engineering, Lublin University of Technology, Nadbystrzycka 26 Street, \\ 20-618 Lublin, Poland; k.palka@pollub.pl \\ 3 Department of Polymer Chemistry, Maria Curie-Skłodowska University in Lublin, \\ M. Curie-Skłodowska Sq. 2, 20-031 Lublin, Poland; 1.szajnecki@umcs.pl \\ * Correspondence: katarzyna.klimek@umlub.pl; Tel.: +48-81-448-7028 or +48-81-448-7020
}

Citation: Nurzynska, A.; Klimek, K.; Palka, K.; Szajnecki, Ł.; Ginalska, G. Curdlan-Based Hydrogels for Potential Application as Dressings for Promotion of Skin Wound Healing-Preliminary In Vitro Studies. Materials 2021, 14, 2344. https://doi.org/10.3390/ma14092344

Academic Editor: Maurice N. Collins

Received: 31 March 2021

Accepted: 28 April 2021

Published: 30 April 2021

Publisher's Note: MDPI stays neutral with regard to jurisdictional claims in published maps and institutional affiliations.

Copyright: (c) 2021 by the authors. Licensee MDPI, Basel, Switzerland. This article is an open access article distributed under the terms and conditions of the Creative Commons Attribution (CC BY) license (https:// creativecommons.org/licenses/by/ $4.0 /)$.

\begin{abstract}
The aim of this work was to establish whether novel curdlan-based hydrogels enriched with $\mathrm{Ca}^{2+}$ ions may be considered as potential candidates for dressings, for the acceleration of skin wound healing. Firstly, biomaterials were allocated for evaluation of structural and mechanical properties. Subsequently, the ability of hydrogels to absorb simulated wound fluid and water vapor permeability, as well their capacity to release calcium ions, was evaluated. The biocompatibility of biomaterials was assessed using normal human skin fibroblasts. Importantly, the main features of the obtained curdlan-based hydrogels were compared with those of KALTOSTAT $^{\circledR}$ (a commercial calcium sodium alginate wound dressing). The obtained results showed that curdlan-based biomaterials possessed a mesoporous structure (pore diameter ranged from 14-48 nm) and exhibited a good ability to absorb simulated wound fluid (swelling ratio close to 974-1229\%). Moreover, in a wet state, they enabled proper water vapor transmission rate $\left(>2000 \mathrm{~g} / \mathrm{m}^{2} /\right.$ day $)$, thanks to their hydrogel structure. Finally, it was found that biomaterial composed of $11 \mathrm{wt}$.\% of curdlan (Cur_11\%) possessed the most desirable biological properties in vitro. It released a beneficial amount of calcium ions to the aqueous environment (approximately $6.12 \mathrm{mM}$ ), which significantly enhanced fibroblast viability and proliferation. Taking into account the beneficial properties of Cur_11\% biomaterial, it seems justified to subject it to more advanced cell culture experiments in vitro and to in vivo studies in order to determine its precise influence on skin wound healing.
\end{abstract}

Keywords: biocompatibility; calcium ions; chronic wounds; hydrogels; skin fibroblasts; wound exudate; bioactive wound dressing

\section{Introduction}

Hard-to-heal wounds (mainly the chronic ones) still constitute a huge problem for current medicine [1-3]. It has been indicated that over 20 million people worldwide suffer from this ailment. Such wounds are associated with many inconveniences for patients, such as reduction of their quality of life, physical limitations, numerous hospital stays, and the need for frequent dressing changes. It is estimated that the global wound care market will consume $\$ 22$ billion dollars in 2024 [4]. Treatment of hard-to-heal wounds with bioactive dressings is crucial to decrease the cost of therapy, increase the quality of patient life, and accelerate wound healing [5-8].

Appropriate dressings for promoting skin wound healing must meet many requirements. They should primarily have the ability to stop bleeding and to absorb a high amount of wound exudate. A moist environment (but not a wet one) at the wound site is considered to be a pivotal condition for the proper healing process $[3,5,6,9,10]$. Dressings 
maintaining moisture decrease the risk of scar formation, enhance re-epithelialization, and facilitate cell migration into the wound. They also support cell viability and proliferation [5-7]. Furthermore, the appropriate dressings cannot strongly adhere to the wound site in order to enable the formation of new tissue without trauma that often occurs during repeated dressing changes $[3,5-7,9,10]$. It is well known that wound dressings constitute a barrier to external contamination. Therefore, they should exhibit mechanical stability during application, which allows for their wearing in a suitable manner, and then easy removal. At the same time, wound dressings should exhibit elastic texture to adapt to the wound bed and should be flexible while the patient is moving [5,11-14]. Permeability of gases is another important feature of wound dressings. Such biomaterials should allow skin to "breathe". Hence, they must enable the exchange of gases, such as $\mathrm{CO}_{2}, \mathrm{O}_{2}$, and $\mathrm{H}_{2} \mathrm{O}[3,5-7]$. On the other hand, biocompatibility is a mandatory property of biomaterials $[15,16]$. Modern dressings should not only be non-toxic, but they should also accelerate the healing process $[3,6]$. Because various types of cells (inter alia monocytes, fibroblasts, keratinocytes) are involved in the healing process, desirable wound dressings should enhance their viability and proliferation, as well as migration [5,6]. In turn, considering the economic aspects, suitable dressings should not be too expensive in order to avoid the high cost of treatment [17-19]. Taking into account all the aforementioned criteria, hydrogels, especially those made from natural polymers, have attracted notable attention in the field of tissue engineering $[3,11,20-25]$. They are fabricated using various techniques, such as phase separation, solvent evaporation, porogen leaching, electrospinning, freeze-drying, or supercritical $\mathrm{CO}_{2}$ drying, which allows for obtaining of porous biomaterials with a high ability to absorb wound exudate $[6,26,27]$.

Curdlan is an unbranched, bacterial $\beta-1,3$-glucan, which possesses beneficial chemical, rheological, and biological properties [28,29]. It is colorless, tasteless, and odorless. Curdlan is not soluble in water (it forms aqueous suspension), but this polysaccharide is soluble in alkaline solutions [16,30]. It also possesses the ability to form non-toxic, flexible but solid hydrogels, when both its aqueous suspension is heated to $55-90^{\circ} \mathrm{C}$ and when its alkaline solution is subjected to ion-exchanging dialysis. Thanks to all the aforementioned features, it is successfully used for tissue engineering applications [15,16,29]. It is also worth highlighting that curdlan belongs to the family of $\beta$-glucans, which exhibit immunostimulatory effects $[16,28,30]$. Therefore, $\beta$-glucans are considered as suitable wound healing agents. They are known to promote wound healing by increasing the infiltration of macrophages, which results in better tissue granulation and collagen deposition, as well as re-epithelialization. Moreover, $\beta$-glucans are characterized by good stability and resistance to wound proteases [31]. Nevertheless, the potential of curdlan as a component of wound dressings is poorly investigated. Basha et al. [32] demonstrated that curdlan/polyvinyl alcohol (PVA) nanofibrous scaffolds possess good swelling behavior and are non-toxic towards myoblast cells (L6 cells). Wojcik et al. [33] fabricated biocompatible curdlan/agarose and curdlan/chitosan dressings with superabsorbent ability. In turn, our recent study demonstrated that curdlan-based biomaterials enriched with copper ions possess antibacterial activity but simultaneously exhibit cytotoxicity towards fibroblast cells [34]. The aim of the current work was to determine whether curdlan-based hydrogels enriched with calcium ions are suitable candidates as dressings for the acceleration of wound healing. The biomaterials were prepared using a new procedure, which combined ion-exchanging dialysis against calcium chloride $\left(\mathrm{CaCl}_{2}\right)$ solution, followed by two-step freezing with subsequent freeze-drying. It is worth underlining that the fabrication procedure of the presented curdlan biomaterials was described in the Polish patent application no. 432848 , "the fabrication method of absorbent biomaterial based on curdlan for medical applications". The obtained biomaterials were subjected to evaluation of their structural, mechanical, and in vitro biological properties. Importantly, the main properties of novel curdlan-based hydrogels were compared with those of KALTOSTAT ${ }^{\circledR}$ (commercial calcium sodium alginate wound dressing). 


\section{Materials and Methods}

\subsection{Materials}

Bovine serum albumin (BSA), formaldehyde solution (36.5-38\%), Hoechst 33342 fluorescent dye, a Live/Dead Cell Double Staining Kit, penicillin-streptomycin solution, phosphate buffered saline (PBS), silica gel with indicator (orange gel), sodium dodecyl sulfate (SDS), thiazolyl blue tetrazolium bromide (MTT), tris-hydroxymethyl aminomethane (TRIS), triton X-100, and trypsin-EDTA solution $(0.25 \%)$ were obtained from Sigma-Aldrich Chemicals, Warsaw, Poland. Curdlan (MW $80 \mathrm{kDa}$ ) was purchased from Wako pure Chemicals Industries, Osaka, Japan, whereas the fetal bovine serum (FBS) was from Pan-Biotech, Aidenbach, Germany. Eagle's Minimum Essential Medium (EMEM) and normal human skin fibroblasts (BJ cell line, CRL-2522 ${ }^{\mathrm{TM}}$ ) were supplied by ATTC, Teddington, UK, while AlexaFluor ${ }^{\mathrm{TM}} 635$ Phalloidin was supplied by Invitrogen, Warsaw, Poland. Calcium chloride $\left(\mathrm{CaCl}_{2}\right)$, dimethyl sulfoxide (DMSO), sodium chloride $(\mathrm{NaCl})$, hydrochloric acid $(\mathrm{HCl})$, and sodium hydroxide $(\mathrm{NaOH})$ were purchased from Avantor Performance Materials, Gliwice, Poland. A calcium ion detection kit (Calcium CPC) was supplied by BioMaxima, Lublin, Poland. Calcium sodium alginate dressing-KALTOSTAT ${ }^{\circledR}(10 \mathrm{~cm} \times 20 \mathrm{~cm})$ was obtained from ConvaTec, Tredegar, UK. Before experiments, a KALTOSTAT ${ }^{\circledR}$ sheet was cut into small discs ( $2.2 \mathrm{~cm}$ in diameter) and sterilized using ethylene oxide.

\subsection{Preparation of Curdlan-Based Biomaterials}

The curdlan-based biomaterials were fabricated according to the procedure described in the Polish patent application no. 432848 ("the fabrication method of absorbent biomaterial based on curdlan for medical applications"). In the first step, solutions containing $5 \mathrm{wt} . \%, 8 \mathrm{wt} . \%$, and $11 \mathrm{wt} . \%$ of curdlan in $0.3 \mathrm{M}$ aqueous $\mathrm{NaOH}$ were prepared using a magnetic stirrer $\left(25^{\circ} \mathrm{C}, 40 \mathrm{rpm}\right.$, Cimarec $+{ }^{\mathrm{TM}}$ Stirrer, ThermoFisher Scientific, Waltham, MA, USA). These solutions were placed into round-shaped forms $(2.2 \mathrm{~cm}$ in diameter) and then were allocated to ion-exchanging dialysis against $2 \%$ of $\mathrm{CaCl}_{2}$ solution $\left(3 \mathrm{~h}, 25^{\circ} \mathrm{C}\right)$. Curdlan cross-linking by $\mathrm{Ca}^{2+}$ ions was undergone in accordance with the mechanism described in detail by Sato et al. [35]. Briefly, during the dialysis process, $\mathrm{Na}^{+}$and $\mathrm{OH}^{-}$ ions outflow outside from of the curdlan solution, which leads to a change of the $\mathrm{pH}$ and, as a consequence, to a conformational transition of curdlan molecules-from random coil to triple helix. Simultaneously, $\mathrm{Ca}^{2+}$ ions inflow to the curdlan solution and cross-link the helical molecules of this polysaccharide (the curdlan-based biomaterial). After dialysis, the obtained solid hydrogels were rinsed with deionized water (three times for $15 \mathrm{~min}$ in order to remove residues of calcium chloride) and placed in a freezer at $-20^{\circ} \mathrm{C}$ for two days, followed by $-80^{\circ} \mathrm{C}$ for $2 \mathrm{~h}$. Finally, they were freeze-dried (LYO GT2-Basic, SRK Systemtechnik $\mathrm{GmbH}$, Riedstadt, Germany) for $24 \mathrm{~h}$. The general fabrication procedure is presented in Figure 1. Resultant dry biomaterials were denoted: Cur_5\%,Cur_8\%, and Cur_ $11 \%$. Before experiments, these biomaterials were sterilized using ethylene oxide.

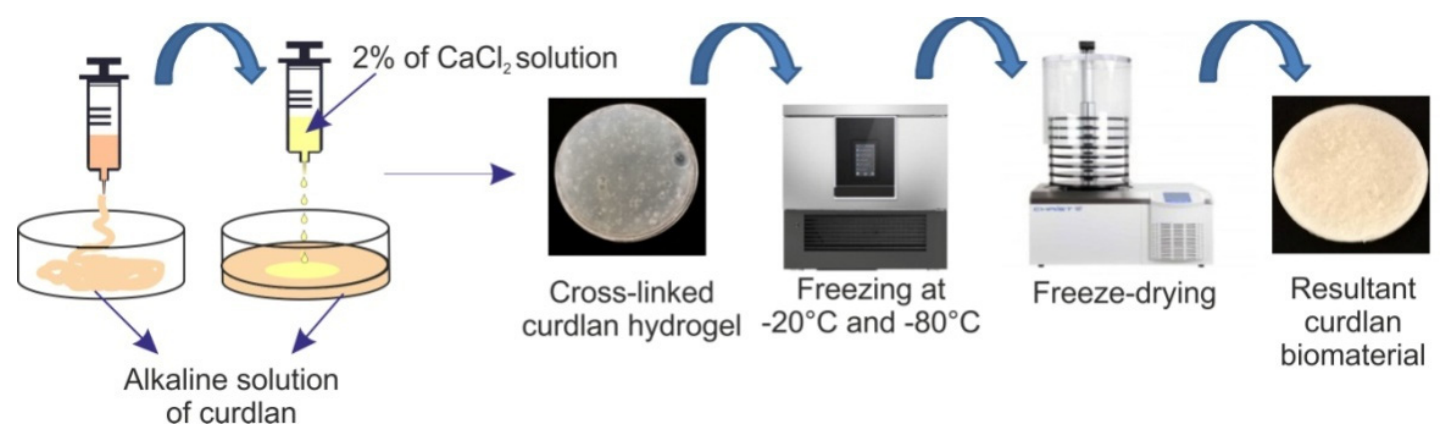

Figure 1. Schematic illustration presenting the general fabrication procedure of curdlan-based biomaterials, according to description in Polish patent application no. 432828. 


\subsection{Assessment of Biomaterial Morphology}

The morphology of the biomaterial specimens was evaluated using a scanning electron microscope (Nova NanoSEM 450, FEI, Oxford, UK) equipped with an Octane Pro EDS detector (EDAX), which enabled chemical analysis and identification of occurring precipitates.

\subsection{Evaluation of Specific Surface Area, Pore Distribution, and Pore Diameter of Biomaterials}

For this experiment, curdlan-based biomaterials were prepared as cylindrical samples ( $5 \mathrm{~mm}$ in diameter and $10 \mathrm{~mm}$ in length). The specific surface area (SSA) of biomaterials was determined by the Brunauer-Emmett-Teller (BET) method from $\mathrm{N}_{2}$ adsorption isotherms obtained at $-196{ }^{\circ} \mathrm{C}$ using ASAP $2020 \mathrm{HD}$ (Micromeritics Inc., Norcross, GA, USA). Before analyses, the biomaterial samples were degassed at $25^{\circ} \mathrm{C}$ for $16 \mathrm{~h}$ and then under vacuum $\left(10^{-5}\right.$ to $\left.10^{-6} \mathrm{mmHg}\right)$ at $25^{\circ} \mathrm{C}$ for $5 \mathrm{~h}$. The original density functional theory (DFT) and classical thermodynamic Barrett-Joyner-Halenda (BJH) theory were used for calculation of pore size distribution and average pore diameter, respectively.

\subsection{Wound Fluid Uptake Test}

In order to assess the ability of biomaterials to absorb wound exudate, the experiment was carried out using simulated wound fluid (SWF), according to a procedure described previously [34]. Briefly, curdlan-based biomaterials and KALTOSTAT ${ }^{\circledR}$ samples were weighed in the dry state and then immersed in SWF (room temperature). The SWF solution was prepared immediately before the experiment using $2.22 \mathrm{~g}$ of $\mathrm{CaCl}_{2}, 23.38 \mathrm{~g}$ of NaCl , $9.69 \mathrm{~g}$ of TRIS, and $20 \mathrm{~g}$ of BSA per $1 \mathrm{~L}$ of deionized water. The final $\mathrm{pH}$ of the obtained solution was 7.5. At fixed time intervals, the specimens were taken out of solution, blotted with tissue paper, re-weighted, and re-immersed. The experiment was performed for $24 \mathrm{~h}$. The swelling ratio was determined using the following Equation (1):

$$
S W(\%)=\frac{(W s-W d)}{W d} \times 100
$$

where Ws denotes the weight of swollen biomaterials (g) and Wd denotes the weight of dry ones $(\mathrm{g})$.

\subsection{Mechanical Properties}

The mechanical properties, namely Young's modulus (E) and tensile strength (TS), were evaluated according to ASTM D638-14 standard recommendations [36]. Curdlanbased biomaterials were prepared as dumbbell-shaped strips (Type V) in accordance with procedure described in Section 2.2. Prior to test, the samples of curdlan-based biomaterials were soaked in SWF for $24 \mathrm{~h}$ (room temperature), to mimic conditions after absorption of wound exudate. Then, the biomaterials were measured using an Autograph AG-X Plus (Shimadzu, Kioto, Japan) testing machine (preload value of $1 \mathrm{~N}$, crosshead moving speed $10 \mathrm{~mm} / \mathrm{min}$ followed by basic load rate $0.5 \mathrm{~mm} / \mathrm{min}$ ). Measurements of Young's modulus were carried out using a non-contact extensometer (TRViewX120S, Shimadzu, Kioto, Japan). In turn, mechanical properties of $\mathrm{KALTOSTAT}^{\circledR}$ biomaterial were not determined because of its unstable structure in a wet state.

\subsection{Water Vapor Transmission Test}

The water vapor transmission test was carried out according to a procedure described previously [34]. For this purpose, silica gel with indicator (5 g) was put into glass vials (diameter of mouth was $1 \mathrm{~cm}$ ) and they were subjected to drying (Drying oven SUP-65, Wamed, Warsaw, Poland). Simultaneously, the samples of curdlan-based biomaterials and KALTOSTAT ${ }^{\circledR}$ specimens were immersed in SWF ( $24 \mathrm{~h}$, room temperature). Then, the vials containing dry silica gel were weighed. The biomaterials were removed from the solution, blotted with tissue paper, and mounted precisely on the mouth of the vials. After $24 \mathrm{~h}$ incubation at $37^{\circ} \mathrm{C}$ and $95 \%$ relative humidity (Heraeus cytoperm 2, Thermo 
Scientific, Waltham, MA, USA), the biomaterials were removed from the vials and the mass of vials with wet silica gel was measured. The water vapor transmission rate (WVTR) was calculated as follows:

$$
W \operatorname{VTR}\left(g / m^{2} / d a y\right)=\frac{W w-W d}{S}
$$

where $W w$ denotes the weight of the vial with wet gel $(\mathrm{g}), W d$ denotes the weight of the vial with dry gel $(\mathrm{g})$, and $S$ denotes the surface of the vial mouth $\left(\mathrm{m}^{2}\right)$.

\subsection{Calcium Ion-Releasing Ability}

To evaluate the capacity of biomaterials to release calcium ions in an aqueous environment, the liquid extracts from specimens were prepared according to ISO 109935:2009 standard recommendations [37]. The samples of curdlan-based biomaterials and KALTOSTAT $^{\circledR}$ specimens were placed into a 12-well plate and EMEM medium with an addition of $2 \%$ FBS was added (extraction ratio was equal to $0.1 \mathrm{~g}$ of biomaterial $/ 1 \mathrm{~mL}$ of EMEM medium). After $24 \mathrm{~h}$ incubation at $37^{\circ} \mathrm{C}$ in a humidified atmosphere of $5 \% \mathrm{CO}_{2}$ and 95\% air (Heraeus cytoperm 2, Thermo Scientific, Waltham, MA, USA), the liquid extracts were collected. The EMEM medium incubated without biomaterials served as a control extract. The concentration of calcium ions in collected solutions was evaluated using the Calcium ion detection kit in accordance with the manufacturer's protocol.

\subsection{Cell Culture Experiments}

The cell culture experiments were performed using normal human skin fibroblasts, i.e., BJ cell line (ATCC, London, UK), as it is known as a good model for the evaluation of wound healing in vitro [33,38-41]. The cells were grown in EMEM medium with an addition of $10 \%$ FBS, $100 \mathrm{U} / \mathrm{mL}$ penicillin, and $100 \mu \mathrm{g} / \mathrm{mL}$ streptomycin. According to ATCC directions, BJ cells were cultured at $37{ }^{\circ} \mathrm{C}$ in a humidified atmosphere of $5 \%$ $\mathrm{CO}_{2}$ and 95\% air (Heraeus cytoperm 2, Thermo Scientific, Waltham, MA, USA). To assess fibroblast response to the tested biomaterials, the liquid extracts from the samples of curdlan-based biomaterials and KALTOSTAT ${ }^{\circledR}$ specimens were prepared according to ISO 10993-5:2009 standard directions [37], as described in Section 2.8. For evaluation of cell viability, extracts were prepared using EMEM supplemented with $2 \%$ FBS, while extracts obtained in EMEM with an addition of 10\% FBS was applied for estimation of cell proliferation. As a control extract, appropriate EMEM medium (with $2 \%$ or $10 \%$ FBS) incubated without biomaterials was utilized. The ISO 10993-5:2009 standard guidelines [37] are commonly applied for the evaluation of biological properties in vitro of biomaterials with biomedical potential [33,34,42-44].

\subsubsection{Cell Viability}

In the first step, BJ cells were seeded in 96-well plates in $100 \mu \mathrm{L}$ of EMEM medium with an addition of $10 \% \mathrm{FBS}$ at a high concentration equal to $1.5 \times 10^{4}$ cells /well. After overnight incubation, the culture medium was replaced with appropriate liquid extracts (obtained in EMEM with 2\% FBS-to minimize cell proliferation) and the plates were incubated for $24 \mathrm{~h}$. Furthermore, 10\% dimethyl sulfoxide (DMSO) solution in culture medium was served as positive control of cytotoxicity. The fibroblast viability was assessed quantitatively via MTT test (as described in details earlier [45]) as well as qualitatively using the Live/Dead Double Staining Kit in accordance with manufacturer protocol. The fibroblasts stained with fluorescent dyes were observed under confocal laser scanning microscope (CLSM, Olympus Fluoview equipped with FV1000, Shinjuku, Japan).

\subsubsection{Cell Proliferation}

Based on results obtained during cell viability evaluation, Cur_11\% biomaterial was selected and its influence on fibroblast proliferation was assessed. The BJ fibroblasts were seeded in 96-well plates in $100 \mu \mathrm{L}$ of EMEM medium with an addition of $10 \%$ FBS at low concentration equal to $2 \times 10^{3}$ cells /well. After overnight incubation, culture medium 
was replaced with biomaterial liquid extracts (obtained in EMEM with 10\% FBS-to allow normal cell proliferation) and the plates were incubated for three and five days. Culture medium incubated without biomaterial was served as a control. After incubation time, the cell proliferation was assessed by the WST- 8 test. The fold increase in cell proliferation was calculated using the following Equation (3):

$$
\text { Fold increase in cell proliferation }=\frac{B-A}{A}
$$

where $A$ denotes the average value of optical density (OD) obtained for the tested group at day three, while $B$ denotes the average value of OD obtained for the tested group at day five.

Moreover, the cells were stained with Hoechst 33342 and AlexaFluor ${ }^{\mathrm{TM}} 635$ Phalloidin fluorescent dyes and observed under CLSM (Olympus Fluoview equipped with FV1000, Shinjuku, Japan).

\subsection{Statistical Analysis}

Most of the analyses were performed at least in three independent experiments and obtained results have been shown as mean values \pm standard deviation (SD). For determination of statistical differences between samples $(p<0.05)$, the unpaired $t$-test or one-way ANOVA test followed by Tukey's multiple comparison test were used (GraphPad Prism 5, Version 5.04 Software).

\section{Results and Discussion}

\subsection{Morphology of Biomaterials}

The scanning electron microscope (SEM) images (Figure 2a) showed that surfaces of all tested curdlan-based samples were covered with sporadically visible precipitates (examples of such precipitates have been marked in red frames). They were primarily composed of calcium and chlorine, as proven by energy dispersive spectroscopy (EDS) spectra (Figure 2a). Most likely, calcium chloride precipitates occurring on biomaterial surfaces should have the ability to dissolve during direct contact with wound exudate. As a consequence, this would lead to an increase in calcium ion concentration at the wound site. This is a very desirable phenomenon because, after skin injury, the concentration of $\mathrm{Ca}^{2+}$ ions gradually increases, which enhances wound healing [46-48]. It was experimentally proved (in vitro and in vivo) that wound dressings possessing the ability to release calcium ions into the wound site promote hemostasis, enhance cell proliferation, and accelerate the formation of granulation tissue [6,20,47-53].

Moreover, SEM images of cross-sections of the biomaterials revealed that they had a porous internal structure (Figure $2 \mathrm{~b}$ ). It is worth pointing out that the use of porous dressings is beneficial for the wound healing process. On the one hand, porosity positively affects the ability of biomaterials to absorb liquids, because porous samples-thanks to higher specific surface area-possess better swelling capacity compared to non-porous ones [54,55]. On the other hand, occurrence of pores within the biomaterial structure allows for the exchange of gases and nutrients, which are necessary for cells $[26,56]$. 


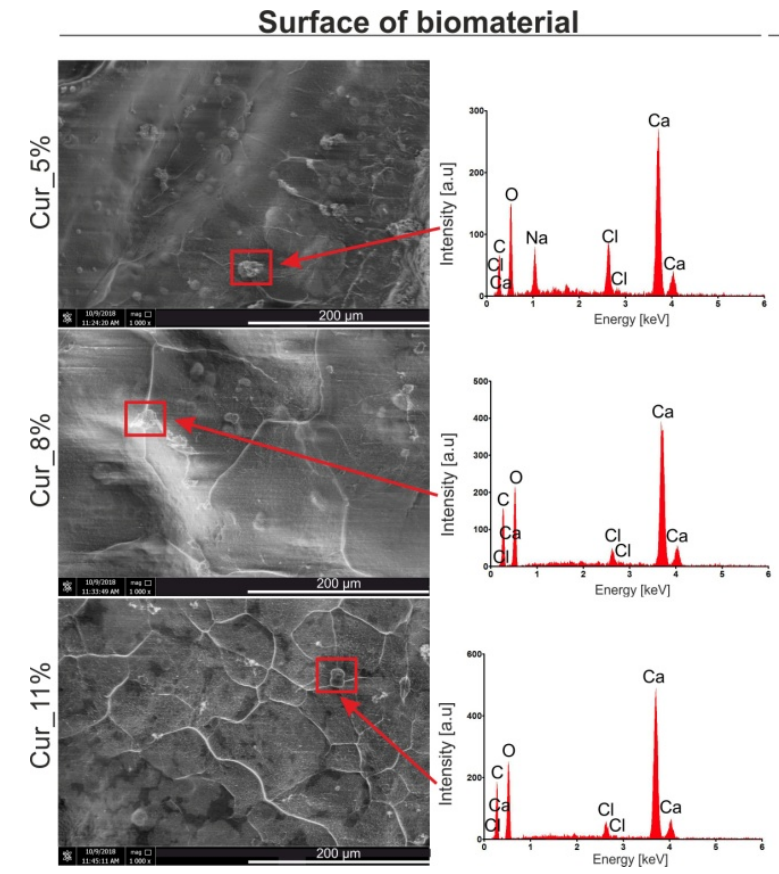

(a)

\section{Cross-section of biomaterial}

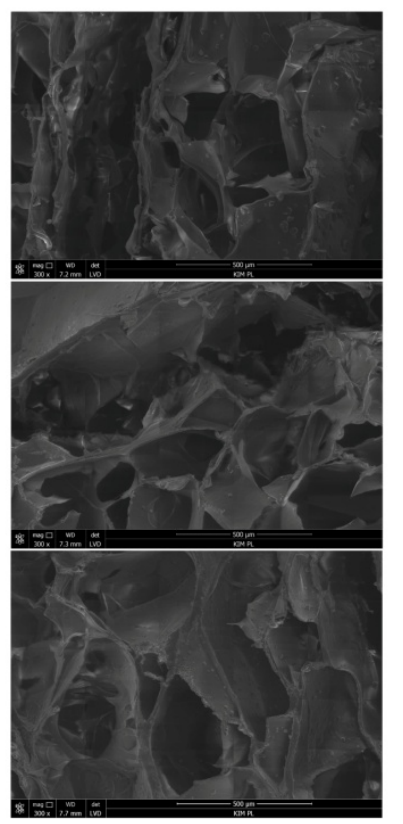

(b)

Figure 2. SEM images of Cur_5\%,Cur_8\%, and Cur_11\% biomaterials and EDS spectra of visible precipitates. Magnification of SEM images: (a) $1000 \times$ (surface of biomaterials) and (b) $300 \times$ (internal cross-section of biomaterials).

\subsection{Specific Surface Area, Pore Distribution, and Pore Diameter of Biomaterials}

Specific surface area (SSA), pore distribution, and pore diameter are key features of porous biomaterials. The SSA is mostly expressed as a ratio between total surface area of a sample and its weight. The value of SSA strictly depends on the size of pores. The pores can be classified as micropores (diameter $<2 \mathrm{~nm}$ ), mesopores (diameter 2-50 nm), or macropores (diameter $>50 \mathrm{~nm}$ ), wherein the presence of micropores mainly determines the value of a specific surface area. It was shown that microporous and mesoporous biomaterials have very good or good absorption ability, due to high specific surface area and high pore volume. In turn, macroporous samples possess relatively poor swelling ability [57-62].

In the case of curdlan-based biomaterials, it was demonstrated that the specific surface area and cumulative pore area of samples increased in the following order: Cur_5\% $>$ Cur_8\% > Cur_11\% (Table 1). Thus, as expected, Cur_5\% and Cur_8\% biomaterials were mainly characterized by the presence of micropores and mesopores, while Cur_ $11 \%$ possessed predominantly mesopores and macropores (Figure 3). Interestingly, because the fabrication method of tested biomaterials was the same, it seems that concentration of curdlan in samples affected their architecture. Some researchers demonstrated that biomaterial porosity decreased along with the increase of polymer concentration due to a higher density in samples [63-66]. Thus, these results can explain our observations. Despite some differences between samples, all tested curdlan-based biomaterials can be classified as mesoporous (based on average pore size values, Table 1). Given the values of specific surface area for curdlan-based biomaterials $\left(50.13-100 \times 10^{-2} \mathrm{~m}^{2} / \mathrm{g}\right.$; Table 1), it seems that they exhibited moderate parameters. For instance, Chen et al. [59] fabricated polyurethane membranes as potential wound dressings. The authors indicated that their specific surface area ranged from 230 to $270 \times 10^{-2} \mathrm{~m}^{2} / \mathrm{g}$. In turn, Zhang et al. [67] prepared three types of porous alginate wound dressings. The specific surface area of these materials ranged from 21.77 to $45.44 \times 10^{-2} \mathrm{~m}^{2} / \mathrm{g}$. 
Table 1. Specific surface area, cumulative pore area, and average pore size of Cur_5\%,Cur_8\%, and Cur_11\% biomaterials.

\begin{tabular}{cccc}
\hline Parameter & Cur_5\% & Cur_8\% & Cur_11\% \\
\hline Specific surface area ${ }^{*}\left[\mathrm{~m}^{2} / \mathrm{g}\right] \times 10^{-2}$ & 100 & 79.04 & 50.13 \\
\hline Cumulative pore area ${ }^{*}\left[\mathrm{~m}^{2} / \mathrm{g}\right] \times 10^{-2}$ & 69.74 & 45.60 & 17.10 \\
\hline Average pore size ${ }^{\$}[\mathrm{~nm}]$ & 14.25 & 27.30 & 47.95 \\
\hline
\end{tabular}

* Specific surface area was calculated from $\mathrm{N}_{2}$ adsorption isotherms using Brunauer-Emmett-Teller (BET) method \# Cumulative pore area was determined from Barrett-Joyner-Halenda (BJH) adsorption cumulative surface area of pores between $1.70 \mathrm{~nm}$ and $300.00 \mathrm{~nm}$ diameter; ${ }^{\$}$ Average pore size was determined from Barrett-Joyner-Halenda $(\mathrm{BJH})$ adsorption average pore width $(4 \mathrm{~V} / \mathrm{A})$.

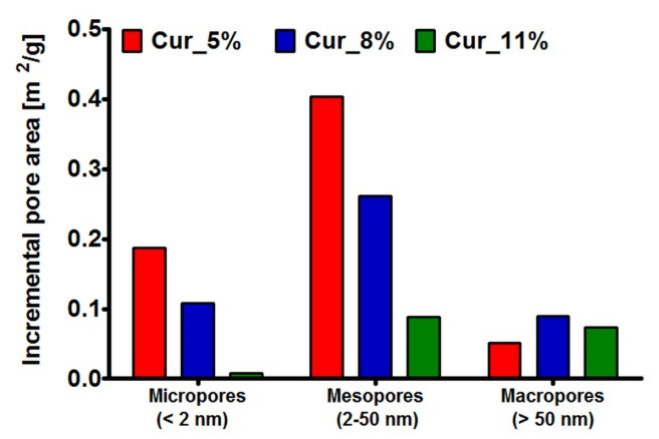

Figure 3. Distribution and pore size within Cur_5\%,Cur_8\%, and Cur_11\% biomaterials.

\subsection{Ability of Biomaterials to Swell in Wound Fluid}

The measurement of sample weights before and after their incubation in simulated wound fluid (SWF) showed that all tested biomaterials possessed good ability to absorb liquid (Figure 4a).

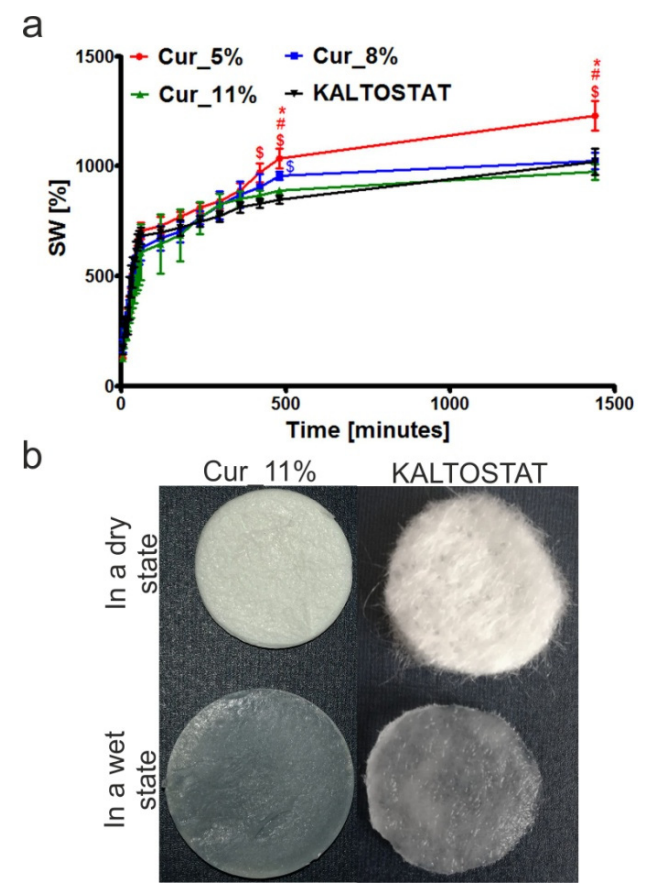

Figure 4. The ability of Cur_5\%,Cur_8\%,Cur_11\%, and KALTOSTAT ${ }^{\circledR}$ biomaterials to absorb simulated wound fluid (SWF) after $24 \mathrm{~h}$ incubation (a) (\# significantly different results compared to Cur_ $8 \%$ biomaterial; ${ }^{*}$ significantly different results compared to Cur_ $11 \%$ biomaterial; ${ }^{\$}$ significantly different results compared to KALTOSTAT ${ }^{\circledR}$; one-way ANOVA test followed by Tukey's multiple comparison, $p<0.05)$. Representative images presenting Cur_11\% and KALTOSTAT ${ }^{\circledR}$ biomaterials in a dry state- before incubation in SWF and in a wet state-after incubation in SWF (b). 
After $24 \mathrm{~h}$ incubation in SWF, the swelling ratio (SW) of Cur_5\%,Cur_8\%, Cur_11\%, and KALTOSTAT ${ }^{\circledR}$ biomaterials was $1229 \pm 66.59 \%, 1025 \pm 36.31 \%, 974 \pm 35.56 \%$, and $1021 \pm 59.19 \%$, respectively. These results confirmed the data obtained from BET theory (Table 1), as the swelling ability of curdlan-based biomaterials decreased along with the decline of their specific surface area. Importantly, all tested curdlan-based biomaterials exhibited swelling ability at least as good as KALTOSTAT ${ }^{\circledR}$. Because this commercial dressing is designed for moderately to heavily exuding wounds (based on manufacturer data from [68]), it seems that all fabricated curdlan-based biomaterials may be considered as promising absorbent dressings.

Moreover, it is worth underlining that, in contrast to the loose, fibrous-like morphology of KALTOSTAT ${ }^{\circledR}$ in a dry state, the fabricated curdlan-based biomaterials possessed a compact, foam-like structure. When all tested samples (curdlan-based and KALTOSTAT ${ }^{\circledR}$ ) were swollen in SWF, they became semi-transparent hydrogel structures. The representative pictures of Cur_ $11 \%$ and KALTOSTAT ${ }^{\circledR}$ biomaterials in dry and wet states have been presented in Figure $4 \mathrm{~b}$. Hydrogel biomaterials have many properties of ideal wound dressings. They are semi-transparent or transparent, allowing for wound observation without removal of the dressing and they have the ability to maintain a moist environment, which enhances wound healing $[5,6,11]$. Furthermore, such dressings are known to reduce pain for patients, because they provide a cooling effect. Hydrogels also exhibit low adherence to the wound site, which decreases pain and overcomes trauma during dressing changes $[5,6]$.

\subsection{Mechanical Properties of Biomaterials}

The swollen curdlan-based hydrogels possessed a compact structure and, simultaneously, they were flexible and could also fit into the site where they were placed (data not shown). The mechanical test was conducted for wet biomaterials and the results have been summarized in Table 2.

Table 2. The values of Young's modulus and tensile strength of Cur_5\%,Cur_8\%, and Cur_11\% after $24 \mathrm{~h}$ incubation in simulated wound fluid (SWF).

\begin{tabular}{ccc}
\hline Biomaterial & $\begin{array}{c}\text { Young's Modulus } \pm \text { SD } \\
{[\mathrm{MPa}]}\end{array}$ & $\begin{array}{c}\text { Tensile Strength } \pm \text { SD } \\
{[\mathrm{MPa}]}\end{array}$ \\
\hline Cur_5\% & $0.179 \pm 0.036{ }^{*}$ & $0.029 \pm 0.002{ }^{*}$ \\
\hline Cur_8\% & $0.189 \pm 0.004{ }^{*}$ & $0.033 \pm 0.011{ }^{*}$ \\
\hline Cur_11\% & $0.296 \pm 0.036$ & $0.051 \pm 0.008$ \\
\hline${ }^{*}$ significantly different results compared to Cur_11\% biomaterial (unpaired $t$-test, $\left.p<0.05\right)$.
\end{tabular}

It was shown that the higher the curdlan concentration in the sample, the better the mechanical properties. Thus, Cur_11\% had the highest values of Young's modulus $(0.296 \pm 0.036 \mathrm{MPa})$ and tensile strength $(0.051 \pm 0.008 \mathrm{MPa})$, which indicates its higher stability compared to the other tested biomaterials. This observation is in accordance with results presented by other researchers, as the hardness and stiffness of the biomaterials increased with greater concentration of polymer in the sample $[69,70]$.

\subsection{Water Vapor Permeability of Biomaterials}

The performed experiment showed that all curdlan-based hydrogels and KALTOSTAT ${ }^{\circledR}$ biomaterial were permeable to water vapor with water vapor transmission rate (WVTR) values above $2000 \mathrm{~g} / \mathrm{m}^{2} /$ day (Figure 5).

The WVTR values for Cur_5\%,Cur_8\%,Cur_11\%, and KALTOSTAT ${ }^{\circledR}$ biomaterials were $2377 \pm 98.23 \mathrm{~g} / \mathrm{m}^{2} /$ day, $2223 \pm 124.8 \mathrm{~g} / \mathrm{m}^{2} /$ day, $2091 \pm 48.41 \mathrm{~g} / \mathrm{m}^{2} /$ day, and $2434 \pm 70.71 \mathrm{~g} / \mathrm{m}^{2} /$ day, respectively. It is considered that evaluation of WVTR is crucial for determination of the biomedical potential of future dressings [14,71]. If WVTR of biomaterials are too low, this can result in exudate accumulation which, as a consequence, may inhibit the healing process and increase risk of infection [72]. The WVTR of normal skin 
is equal to $204 \mathrm{~g} / \mathrm{m}^{2} /$ day, while injured skin possesses significantly higher permeability with WVTR ranging from $279 \mathrm{~g} / \mathrm{m}^{2} /$ day to $5138 \mathrm{~g} / \mathrm{m}^{2} /$ day [71]. An "ideal" dressing should reduce excessive dehydration of skin as well as preventing exudate buildup. Thus, its WVTR should be close to $2000-2500 \mathrm{~g} / \mathrm{m}^{2} /$ day $[34,71,73]$. The results obtained for curdlan-based biomaterials and KALTOSTAT ${ }^{\circledR}$ dressing indicate that they should allow for proper water vapor permeability and should maintain a moist environment at the wound site without undue dehydration.

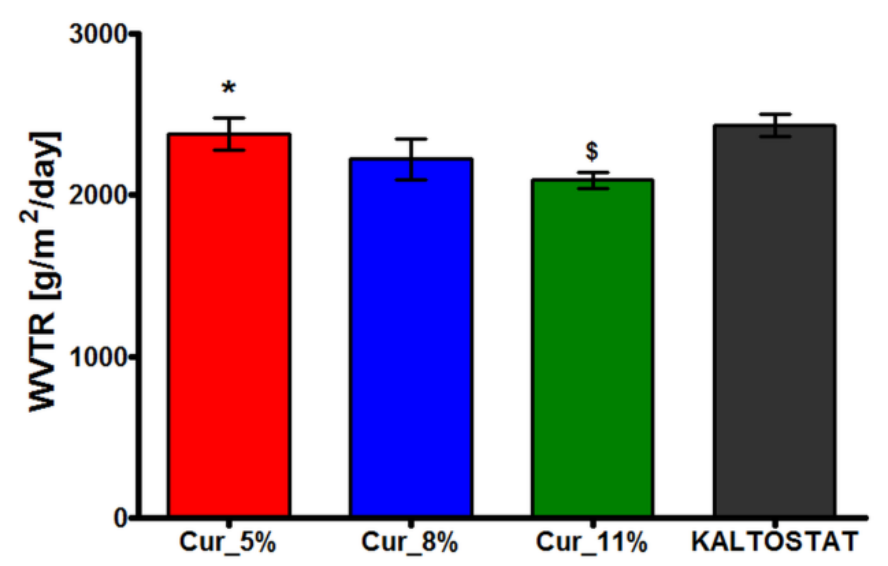

Figure 5. Water vapor transmission rate (WVTR) of Cur_5\%,Cur_8\%,Cur_11\%, and KALTOSTAT ${ }^{\circledR}$ biomaterials. (* significantly different results compared to Cur_11\% hydrogel; ${ }^{\$}$ significantly different results compared to KALTOSTAT ${ }^{\circledR}$ biomaterial; one-way ANOVA followed by Tukey's multiple comparison test, $p<0.05)$.

\subsection{Ability of Biomaterials to Release Calcium Ions}

The calcium ion detection kit revealed that all the tested biomaterials possessed a huge capacity to release $\mathrm{Ca}^{2+}$ ions to the culture medium (Figure 6). After $24 \mathrm{~h}$ incubation, the concentrations of $\mathrm{Ca}^{2+}$ ions in extracts obtained from Cur_5\%,Cur_8\%,Cur_11\%, and KALTOSTAT $^{\circledR}$ biomaterials were approximately five- to six-fold higher $(p<0.05)$ than the concentrations of these ions in the control extract (culture medium incubated without biomaterials). Of the tested biomaterials, Cur_ $11 \%$ released the greatest amount of $\mathrm{Ca}^{2+}$ ions.

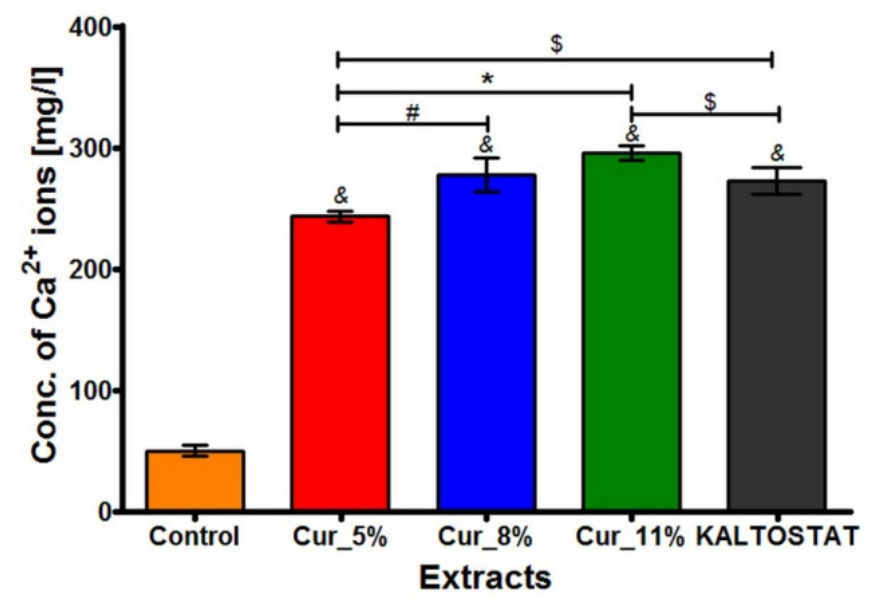

Figure 6. Concentration of calcium ions released from Cur_5\%,Cur_8\%,Cur_11\%, and KALTOSTAT ${ }^{\circledR}$ biomaterials after $24 \mathrm{~h}$ incubation in culture medium (EMEM with addition of $2 \% \mathrm{FBS}$ ). Extracts were prepared according to ISO 10993-5:2009 standard recommendations [37]. (\& significantly different results compared to control extract—culture medium incubated without biomaterials; ${ }^{\text {\# }}$ significantly different results compared to Cur_8\% extract; * significantly different results compared to Cur_11\% extract; ${ }^{\$}$ significantly different results compared to KALTOSTAT ${ }^{\circledR}$ extract; one-way ANOVA followed by Tukey's multiple comparison test, $p<0.05$ ). 
It is worth underlining that calcium ions $\left(\mathrm{Ca}^{2+}\right.$ ions) play a pivotal role in wound healing [46-48]. Immediately after skin injury, the concentration of these ions gradually increases, while the highest level is observed during the inflammation and proliferative phases. Generally, it was found that the concentration of calcium ions during wound healing increases from $0.5 \mathrm{mM}$ (basal layer of skin) to above $1.4 \mathrm{mM}$ (in the stratum granulosum). The $\mathrm{Ca}^{2+}$ ions are crucial for the formation of fibrin clots as they constitute clotting factor IV. They are released by platelets and their presence stimulates the synthesis and release of other clotting factors (i.e., VII, IX, and X). They also promote conversion of prothrombin to thrombin. During the next two phases (inflammation and proliferation), $\mathrm{Ca}^{2+}$ ions induce an influx of inflammatory cells, fibroblasts, and keratinocytes. They also regulate proliferation of fibroblasts and keratinocytes [46,53,74-76]. Thus, given the high significance of calcium ions in early phases of wound healing, some bioactive dressings for the treatment of chronic wounds (e.g., $\operatorname{KALTOSTAT}^{\circledR}$ ) have the ability to release $\mathrm{Ca}^{2+}$, which significantly accelerates skin regeneration $[3,7,20,77]$. In our study, we demonstrated that after $24 \mathrm{~h}$ incubation, the concentration of calcium ions released from tested samples to the culture medium was approx. $4.82-6.12 \mathrm{mM}$ for curdlan-based biomaterials and approx. $5.72 \mathrm{mM}$ for KALTOSTAT ${ }^{\circledR}$. These results seem to be promising when compared with data obtained by Ågren [50]. The author evaluated the biomedical potential of four commercial alginate dressings (ALGOSTERIL, Comfeel Alginate, KALTOSTAT, and SORBSAN), as well as polyurethane film dressing (control sample) using a wound model in domestic pigs. After $24 \mathrm{~h}$ treatment with alginate-based dressings and polyurethane film, the concentration of calcium ions in the collected wound exudate was $5.0-11.7 \mathrm{mM}$ and $2.8 \mathrm{mM}$, respectively. Moreover, it was shown that all alginate-based biomaterials enhanced re-epithelialization of pig skin significantly better, compared to control (polyurethane film dressing). Thus, these results may suggest that curdlan-based biomaterials release a suitable amount of calcium ions to ensure proper wound healing.

\subsection{Fibroblast Viability}

The thiazolyl blue tetrazolium bromide (MTT) assay demonstrated that extracts obtained from Cur_5\%,Cur_8\%,Cur_11\%, and KALTOSTAT ${ }^{\circledR}$ were not only non-toxic towards BJ fibroblasts, but also supported viability of these cells (Figure 7a). Thus, after $24 \mathrm{~h}$ incubation, the viability of BJ cells treated with extracts from Cur_5\%, Cur_ $8 \%$, Cur_11\%, and KALTOSTAT ${ }^{\circledR}$ was $103.30 \pm 1.91 \%, 114.30 \pm 8.14 \%, 120.60 \pm 3.17 \%$, and $112.70 \pm 5.85 \%$, respectively, in comparison with the viability of cells grown in the control extract (culture medium incubated without biomaterials, i.e., negative control of cytotoxicity). The confocal laser scanning microscope (CLSM) observations confirmed the results obtained with the MTT test. The fibroblast cells treated with the control extract and extracts from Cur_5\%,Cur_8\%,Cur_11\%, and KALTOSTAT ${ }^{\circledR}$ were viable, and no dead cells were observed. In turn, the cells incubated with DMSO solution (positive control of cytotoxicity) were mainly dead (Figure $7 \mathrm{~b}$ ).

Taking into consideration obtained results (Figure 7a,b), it should be concluded that fibroblast viability is most likely correlated with the ability of biomaterials to release calcium ions to the culture medium (Figure 6). Extract from Cur_11\% dressing exhibited the most beneficial effect on fibroblast viability and it contained the highest concentration of calcium ions compared to both the control extract as well as extracts from other biomaterials. Considering the fact that extract obtained from Cur_11\% biomaterial enhanced fibroblast viability more potently than other tested biomaterials, it was allocated to the next cell culture experiment-evaluation of cell proliferation. 
a
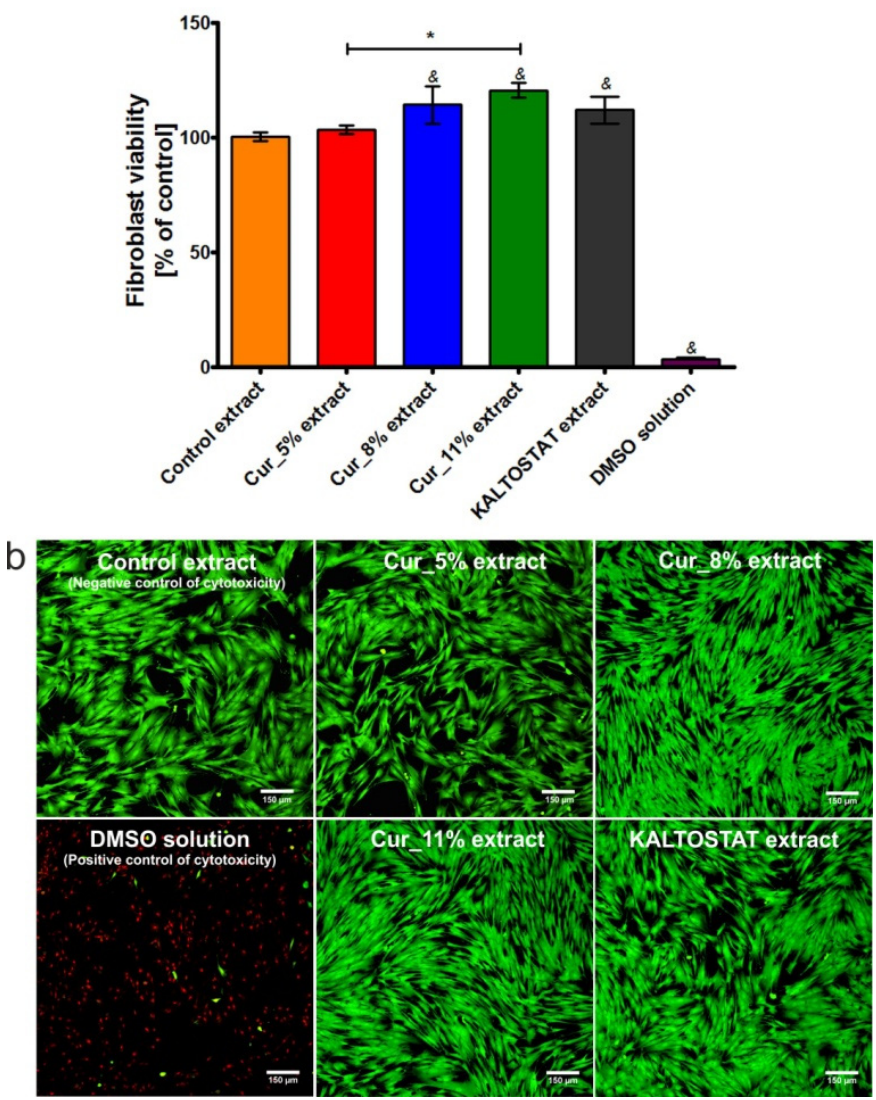

Figure 7. Fibroblast viability (BJ cell line, ATCC CRL-2522 ${ }^{\mathrm{TM}}$ ) after $24 \mathrm{~h}$ incubation with extracts obtained from Cur_5\%,Cur_8\%,Cur_11\%, and KALTOSTAT ${ }^{\circledR}$ biomaterials. Extracts were prepared in culture medium (EMEM with addition of 2\% FBS) according to ISO 10993-5:2009 standard recommendations [37]. Culture medium incubated without biomaterials (control extract) and 10\% DMSO solution were used as negative and positive controls of cytotoxicity, respectively. The results obtained using the MTT assay (a) ( $\&$ significantly different results compared to culture medium incubated without biomaterials (control extract); ${ }^{*}$ significantly different results compared to Cur_11\% extract; one-way ANOVA followed by Tukey's multiple comparison test, $p<0.05$ ). The confocal laser scanning microscope (CLSM) images presenting viable cells (green fluorescence) and dead cells (red fluorescence) after staining with Live/Dead Cell Double Staining Kit (b); magnification 100x, scale bar equals $150 \mu \mathrm{m}$.

\subsection{Fibroblast Proliferation}

The WST-8 assay revealed that extract obtained from Cur_11\% biomaterial promoted growth and proliferation of BJ cells compared to the control extract (Table 3). Moreover, the CLSM images (Figure 8) showed that the number of cells treated with Cur_11\% extract was higher compared to the number of control cells. Thus, these results are in good agreement with the data obtained during the cell viability evaluation (Figure 7a,b), as such extract also significantly promoted fibroblast viability compared to control extract. 
Table 3. Influence of Cur_11\% extract and control extract (culture medium incubated without biomaterial) on skin fibroblast proliferation (BJ cell line, ATCC CRL-2522 ${ }^{\mathrm{TM}}$ ). Extracts were prepared in culture medium (EMEM with addition of 10\% FBS) according to ISO 10993-5:2009 standard recommendations [37]. The results were expressed as values of fold increase in cell proliferation based on data obtained using WST-8 assay after 3- and 5-day incubation.

\begin{tabular}{cc}
\hline Sample & Fold Increase in Cell Proliferation \\
\hline Control extract & 0.79 \\
\hline Cur_11\% extract & 1.16 \\
\hline
\end{tabular}

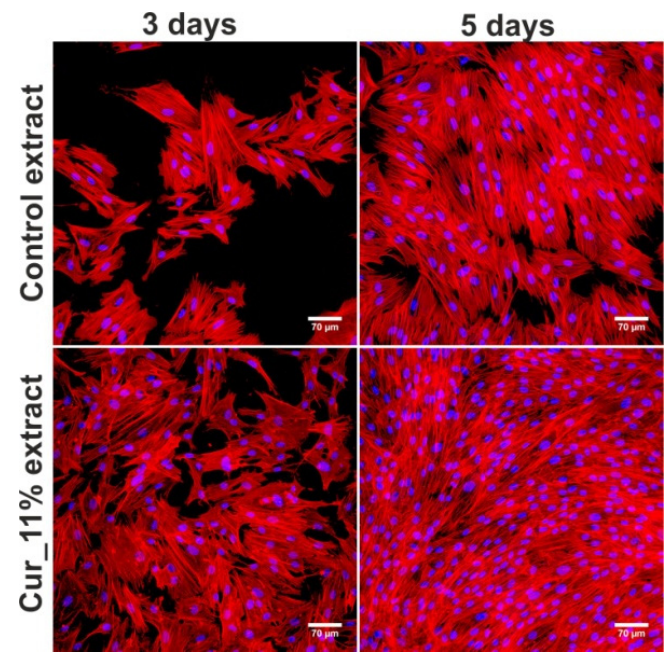

Figure 8. The confocal laser scanning microscope (CLSM) images presenting skin fibroblasts (BJ cell line, ATCC CRL-2522 ${ }^{\mathrm{TM}}$ ) after three- and five-day incubation with Cur_11\% extract. Culture medium incubated without biomaterial was served as a control. Extracts were prepared in culture medium (EMEM with addition of 10\% FBS) according to ISO 10993-5:2009 standard recommendations [37]. Nuclei-blue fluorescence after Hoechst 33342 staining; cytoskeletal filaments-red fluorescence after AlexaFluor ${ }^{\mathrm{TM}} 635$ phalloidin staining; magnification $200 \times$, scale bar equals $70 \mu \mathrm{m}$.

\section{Conclusions}

To sum up, three curdlan-based biomaterials, namely Cur_5\%,Cur_8\%, and Cur_11\%, were fabricated via ion-exchanging dialysis against a $\mathrm{CaCl}_{2}$ solution followed by two-step freezing, and subsequent freeze-drying. Combination of these three techniques permitted the production of curdlan-based biomaterials, which exhibited good capacity to absorb simulated wound fluid compared to the commercially available dressing-KALTOSTAT ${ }^{\circledR}$. New curdlan-based biomaterials became beneficial hydrogel structures in the wet state and simultaneously allowed for proper water vapor permeability. Moreover, they possessed the ability to release great amounts of calcium ions to the surrounding environment, which are essential during wound healing. Considering the main requirements for bioactive wound dressings, Cur_11\% biomaterial had the most desired properties. Importantly, it possessed similar absorbent properties to KALTOSTAT $^{\circledR}$, but supported fibroblast viability significantly better than this commercial dressing. Cur_11\% biomaterial was also found to promote fibroblast proliferation. Thus, Cur_11\% hydrogel may be considered as a promising bioactive dressing for wound healing with moderate to high amounts of exudate.

\section{Patents}

The fabrication procedure of curdlan dressings was claimed in the Polish patent application no. 432848 ("The fabrication method of absorbent biomaterial based on curdlan for medical applications"). 
Author Contributions: Conceptualization, K.K.; methodology, K.K. and K.P.; software, A.N., K.K., K.P. and Ł.S.; validation, A.N., K.K. and K.P.; formal analysis, A.N., K.K., K.P. and Ł.S.; investigation, A.N., K.K., K.P. and Ł.S.; resources, G.G.; data curation, K.K. and K.P.; writing-original draft preparation, A.N., K.K. and K.P.; writing-review and editing, K.K.; visualization, A.N.; supervision, G.G.; project administration, G.G.; funding acquisition, G.G. All authors have read and agreed to the published version of the manuscript.

Funding: This research was funded by DS2 project of Medical University of Lublin, Poland. This paper was developed using the equipment purchased within agreement No. POPW.01.03.00-06010/09-00 Operational Program Development of Eastern Poland 2007-2013, Priority Axis I, Modern Economy, Operations 1.3. Innovations Promotion.

Institutional Review Board Statement: Not applicable.

Informed Consent Statement: Not applicable.

Data Availability Statement: Data available on reasonable request.

Acknowledgments: The authors would like to thank Michal Wojcik from Department of Biochemistry and Biotechnology, Medical University of Lublin, Poland for the help with confocal laser scanning microscopy (CLSM) analysis. They also would like to thank Anna Gawryszuk-Rżysko from Analytical Laboratory, Maria-Curie Skłodowska University, Lublin, Poland and Aleksandra Bogusz from Department of Ecotoxicology, Institute of Environmental Protection-National Research Institute, Warszawa, Poland for the help with nitrogen adsorption-desorption isotherms analysis.

Conflicts of Interest: The authors declare no conflict of interest.

\section{References}

1. Ellis, S.; Lin, E.J.; Tartar, D. Immunology of Wound Healing. Curr. Dermatol. Rep. 2018, 7, 350-358. [CrossRef]

2. Velnar, T.; Bailey, T.; Smrkolj, V. The wound healing process: An overview of the cellular and molecular mechanisms. J. Int. Med. Res. 2009, 37, 1528-1542. [CrossRef]

3. Aderibigbe, B.A.; Buyana, B. Alginate in wound dressings. Pharmaceutics 2018, 10, 42. [CrossRef] [PubMed]

4. Sen, C.K. Human Wounds and Its Burden: An Updated Compendium of Estimates. Adv. Wound Care 2019, 8, 39-48. [CrossRef]

5. Koehler, J.; Brandl, F.P.; Goepferich, A.M. Hydrogel wound dressings for bioactive treatment of acute and chronic wounds. Eur. Polym. J. 2018, 100, 1-11. [CrossRef]

6. Gupta, B.; Agarwal, R.; Alam, M.S. Chapter 9-Hydrogels for wound healing applications. In Biomedical Hydrogels; Rimmer, S., Ed.; Woodhead Publishing Limited: Cambridge, UK, 2011; pp. 184-227.

7. Moura, L.I.F.; Dias, A.M.A.; Carvalho, E.; De Sousa, H.C. Recent advances on the development of wound dressings for diabetic foot ulcer treatment-A review. Acta Biomater. 2013, 9, 7093-7114. [CrossRef] [PubMed]

8. Bumpus, K.; Maier, M.A. The ABC's of wound care. Curr. Cardiol. Rep. 2013, 15, 346. [CrossRef] [PubMed]

9. Fulton, J.A.; Blasiole, K.N.; Cottingham, T.; Tornero, M.; Graves, M.; Smith, L.G.; Mirza, S.; Mostow, E.N. Wound dressing absorption: A comparative study. Adv. Ski. Wound Care 2012, 25, 315-320. [CrossRef] [PubMed]

10. Ngadaonye, J.I.; Geever, L.M.; Killion, J.; Higginbotham, C.L. Development of novel chitosan-poly(N,N-diethylacrylamide) IPN films for potential wound dressing and biomedical applications. J. Polym. Res. 2013, 20, 161. [CrossRef]

11. Kiselioviene, S.; Baniukaitiene, O.; Harkavenko, V.; Babenko, N.A.; Liesiene, J. Cellulose Hydrogel sheets for Wound Dressings. Cellul. Chem. Technol. Cellul. Chem. Technol. 2016, 50, 915-923.

12. Devi, M.P.; Sekar, M.; Chamundeswari, M.; Moorthy, A.; Krithiga, G.; Murugan, N.S.; Sastry, T.P. A novel wound dressing material-fibrin-chitosan-sodium alginate. Indian Acad. Sci. 2012, 35, 1157-1163.

13. Zaman, H.U.; Islam, J.M.M.; Khan, M.A.; Khan, R.A. Physico-mechanical properties of wound dressing material and its biomedical application. J. Mech. Behav. Biomed. Mater. 2011, 4, 1369-1375. [CrossRef] [PubMed]

14. Rezvanian, M.; Cairul, M.; Mohd, I.; Ng, S. Development and physicochemical characterization of alginate composite film loaded with simvastatin as a potential wound dressing. Carbohydr. Polym. 2016, 137, 295-304. [CrossRef] [PubMed]

15. Klimek, K.; Przekora, A.; Pałka, K.; Ginalska, G. New method for the fabrication of highly osteoconductive $\beta-1,3-$ glucan/HA scaffold for bone tissue engineering: Structural, mechanical, and biological characterization. J. Biomed. Mater. Res. Part A 2016, 104A, 2528-2536. [CrossRef]

16. Klimek, K.; Przekora, A.; Benko, A.; Niemiec, W.; Blazewicz, M.; Ginalska, G. The use of calcium ions instead of heat treatment for $\beta$-1,3-glucan gelation improves biocompatibility of the $\beta$-1,3-glucan/HA bone scaffold. Carbohydr. Polym. 2017, 164, 170-178. [CrossRef] [PubMed]

17. Sood, A.; Granick, M.S.; Tomaselli, N.L. Wound Dressings and Comparative Effectiveness Data. Adv. Wound Care 2014, 3, 511-529. [CrossRef] 
18. Veličković, V.M.; Chadwick, P.; Rippon, M.G.; Ilić, I.; McGlone, E.R.; Gebreslassie, M.; Csernus, M.; Streit, I.; Bordeanu, A.; Kaspar, D.; et al. Cost-effectiveness of superabsorbent wound dressing versus standard of care in patients with moderate-to-highly exuding leg ulcers. J. Wound Care 2020, 29, 235-246. [CrossRef]

19. Kamoun, E.A.; Kenawy, E.S.; Chen, X. A review on polymeric hydrogel membranes for wound dressing applications: PVA-based hydrogel dressings. J. Adv. Res. 2017, 8, 217-233. [CrossRef]

20. Hampton, S. The role of alginate dressings in wound healing. Diabet. Foot 2004, 7, 162-167.

21. Ahmed, S.; Ikram, S. Chitosan Based Scaffolds and Their Applications in Wound Healing. Achiev. Life Sci. 2016, 10, 27-37. [CrossRef]

22. Pallaske, F.; Pallaske, A.; Herklotz, K.; Boese-Landgraf, J. The significance of collagen dressings in wound management: A review. J. Wound Care 2018, 27, 692-702. [CrossRef] [PubMed]

23. Helary, C.; Abed, A.; Mosser, G.; Louedec, L.; Letourneur, D.; Coradin, T.; Giraud-Guille, M.M.; Pelle, A.M. Evaluation of dense collagen matrices as medicated wound dressing for the treatment of cutaneous chronic wounds. Biomater. Sci. 2015, 3, 373-382. [CrossRef] [PubMed]

24. Graça, M.F.P.; Miguel, S.P.; Cabral, C.S.D.; Correia, I.J. Hyaluronic acid-Based wound dressings: A review. Carbohydr. Polym. 2020, 241, 116364. [CrossRef]

25. Larrañeta, E.; Henry, M.; Irwin, N.J.; Trotter, J.; Perminova, A.A.; Donnelly, R.F. Synthesis and characterization of hyaluronic acid hydrogels crosslinked using a solvent-free process for potential biomedical applications. Carbohydr. Polym. 2018, 181, 1194-1205. [CrossRef] [PubMed]

26. Sujka, W.; Draczynski, Z.; Kolesinska, B.; Latanska, I.; Jastrzebski, Z.; Rybak, Z.; Zywicka, B. Influence of porous dressings based on butyric-acetic chitin co-polymer on biological processes in vitro and in vivo. Materials 2019, 12, 970. [CrossRef] [PubMed]

27. Baldino, L.; Cardea, S.; Scognamiglio, M.; Reverchon, E. A new tool to produce alginate-based aerogels for medical applications, by supercritical gel drying. J. Supercrit. Fluids 2019, 146, 152-158. [CrossRef]

28. Zhang, R.; Edgar, K.J. Properties, chemistry, and applications of the bioactive polysaccharide curdlan. Biomacromolecules 2014, 15, 1079-1096. [CrossRef]

29. Klimek, K.; Benko, A.; Pałka, K.; Ludwiczuk, A.; Ginalska, G. Ion-exchanging dialysis as an effective method for protein entrapment in curdlan hydrogel. Mater. Sci. Eng. C 2019, 105, 110025. [CrossRef]

30. West, T.P. Production of the Polysaccharide Curdlan by Agrobacterium species on Processing Coproducts and Plant Lignocellulosic Hydrolysates. Fermentation 2020, 6, 16. [CrossRef]

31. Majtan, J.; Jesenak, M. $\beta$-Glucans: Multi-functional modulator of wound healing. Molecules 2018, 23, 806. [CrossRef]

32. Basha, R.Y.; Kumar, S.T.; Doble, M. Electrospun Nanofibers of Curdlan ( $\beta-1,3$ Glucan) Blend as Potential Skin Scaffold Material. Macromol. Mater. Eng. 2016, 302, 1600417. [CrossRef]

33. Wojcik, M.; Kazimierczak, P.; Benko, A.; Palka, K.; Vivcharenko, V.; Przekora, A. Superabsorbent curdlan-based foam dressings with typical hydrocolloinds properties for highly exuding wound management. Mater. Sci. Eng. C 2021, in press. [CrossRef]

34. Nurzynska, A.; Klimek, K.; Swierzycka, I.; Palka, K.; Ginalska, G. Porous Curdlan-Based Hydrogels Modified with Copper Ions as Potential Dressings for Prevention and Management of Bacterial Wound Infection-An In Vitro Assessment. Polymers 2020, 12, 1893. [CrossRef]

35. Sato, M.; Nobe, M.; Dobashi, T.; Yamamoto, T.; Konno, A. Multifold curdlan gel formation by dialysis into aqueous solutions of metal salts. Colloid Polym. Sci. 2005, 284, 293-300. [CrossRef]

36. ASTM D638-14. Standard Test Method for Tensile Properties of Plastics; ASTM International: West Conshohocken, PA, USA, 2014.

37. ISO 10993-5:2009. Biological Evaluation of Medical Devices-Part 5: Tests for In Vitro Cytotoxicity; International Organization for Standarization: Genewa, Switzerland, 2009.

38. Bilgi, A.; Biber Muftuler, F.Z.; Akman, L.; Medine, E.I.; Bilgi, P.T.; Guldu, O.K.; Gokulu, S.G.; Tekin, V.; Terek, M.C. In Vitro Determination of Wound Healing of Axonge. Wounds 2017, 29, 209-214.

39. Bi, Q.; Liu, J.; Wang, X.; Sun, F. Downregulation of miR-27b promotes skin wound healing in a rat model of scald burn by promoting fibroblast proliferation. Exp. Ther. Med. 2020, 20, 1. [CrossRef] [PubMed]

40. Safina, I.; Bourdo, S.E.; Algazali, K.M.; Kannarpady, G.; Watanabe, F.; Vang, K.B.; Biris, A.S. Graphene-based 2D constructs for enhanced fibroblast support. PLoS ONE 2020, 15, e0232670. [CrossRef] [PubMed]

41. Balekar, N.; Nakpheng, T.; Srichana, T. Wound-healing potential of grandiflorenic acid isolated from Wedelia trilobata (L.) leaves. Songklanakarin J. Sci. Technol. 2013, 35, 537-546.

42. Roy, N.; Saha, N.; Humpolicek, P.; Saha, P. Permeability and biocompatibility of novel medicated hydrogel wound dressings. Soft Mater. 2010, 8, 338-357. [CrossRef]

43. Tyliszczak, B.; Drabczyk, A.; Kudłacik-Kramarczyk, S.; Bialik-Wąs, K.; Sobczak-Kupiec, A. In vitro cytotoxicity of hydrogels based on chitosan and modified with gold nanoparticles. J. Polym. Res. 2017, 24, 1-7. [CrossRef]

44. Kim, J.T.; Lee, D.Y.; Kim, T.H.; Song, Y.S.; Cho, N.I. Biocompatibility of hyaluronic acid hydrogels prepared by porous hyaluronic acid microbeads. Met. Mater. Int. 2014, 20, 555-563. [CrossRef]

45. Klimek, K.; Belcarz, A.; Pazik, R.; Sobierajska, P.; Han, T.; Wiglusz, R.J.; Ginalska, G. "False” cytotoxicity of ions-adsorbing hydroxyapatite-Corrected method of cytotoxicity evaluation for ceramics of high specific surface area. Mater. Sci. Eng. C 2016, 65, 70-79. [CrossRef] 
46. Lansdown, A.B.G. Calcium: A potential central regulator in wound healing in the skin. Wound Repair Regen. 2002, 10, 271-285. [CrossRef] [PubMed]

47. Kawai, K.; Larson, B.J.; Ishise, H.; Carre, A.L.; Nishimoto, S.; Lorenz, H.P. Calcium-Based Nanoparticles Accelerate Skin Wound Healing. PLoS ONE 2011, 6, e27106. [CrossRef]

48. Wood, W. Wound healing: Calcium flashes illuminate early events. Curr. Biol. 2012, 22, R14-R16. [CrossRef] [PubMed]

49. Wang, T.; Gu, Q.; Zhao, J.; Mei, J.; Shao, M.; Pan, Y.; Zhang, J.; Wu, H.; Zhang, Z.; Liu, F. Calcium alginate enhances wound healing by up-regulating the ratio of collagen types I/III in diabetic rats. Int. J. Clin. Exp. Pathol. 2015, 8, 6636-6645. [PubMed]

50. Ågren, M.S. Four alginate dressings in the treatment of partial thickness wounds: A comparative experimental study. Br. J. Plast. Surg. 1996, 49, 129-134. [CrossRef]

51. Doyle, J.W.; Roth, T.P.; Smith, R.M.; Li, Y.Q.; Dunn, R.M. Effect of calcium alginate on cellular wound healing processes modeled in vitro. J. Biomed. Mater. Res. 1996, 32, 561-568. [CrossRef]

52. Attwood, A.I. Calcium alginate dressing accelerates split skin graft donor site healing. Br. J. Plast. Surg. 1989, 42, 373-379. [CrossRef]

53. Oda, Y.; Tu, C.L.; Menendez, A.; Nguyen, T.; Bikle, D.D. Vitamin D and calcium regulation of epidermal wound healing. J. Steroid Biochem. Mol. Biol. 2016, 164, 379-385. [CrossRef]

54. Cao, D.; Zhang, Y.; Cui, Z.; Du, Y.; Shi, Z. New strategy for design and fabrication of polymer hydrogel with tunable porosity as artificial corneal skirt. Mater. Sci. Eng. C 2017, 70, 665-672. [CrossRef] [PubMed]

55. Kaewprasit, C. Effect of Adsorbed Water on the Specific Surface Area of Some Standards Cotton. In Proceedings of the Beltwide Cotton Conference, Orlandao, FL, USA, 3-7 January 1999; pp. 710-712.

56. Okur, M.E.; Karantas, I.D.; Şenyiğit, Z.; Üstündağ Okur, N.; Siafaka, P.I. Recent trends on wound management: New therapeutic choices based on polymeric carriers. Asian J. Pharm. Sci. 2020, 15, 661-684. [CrossRef]

57. Galarneau, A.; Mehlhorn, D.; Guenneau, F.; Coasne, B.; Villemot, F.; Minoux, D.; Aquino, C.; Dath, J.P. Specific Surface Area Determination for Microporous/Mesoporous Materials: The Case of Mesoporous FAU-Y Zeolites. Langmuir 2018, 34, 14134-14142. [CrossRef] [PubMed]

58. Chen, J.; Yan, W.; Townsend, E.J.; Feng, J.; Pan, L.; Del Angel Hernandez, V.; Faul, C.F.J. Tunable Surface Area, Porosity, and Function in Conjugated Microporous Polymers. Angew. Chem. Int. Ed. 2019, 58, 11715-11719. [CrossRef] [PubMed]

59. Chen, Y.; Yan, L.; Yuan, T.; Zhang, Q.; Fan, H. Asymmetric Polyurethane Membrane with In Situ-Generated $\mathrm{Nano}^{-T i O}{ }_{2}$ as Wound Dressing. J. Appl. Polym. Sci. 2011, 119, 1532-1541. [CrossRef]

60. Sang, G.; Liu, S.; Zhang, R.; Elsworth, D.; He, L. Nanopore characterization of mine roof shales by SANS, nitrogen adsorption, and mercury intrusion: Impact on water adsorption/retention behavior. Int. J. Coal Geol. 2018, 200, 173-185. [CrossRef]

61. Lee, J.; Choi, Y.C. Pore structure characteristics of foam composite with active carbon. Materials 2020, 13, 4038. [CrossRef]

62. Ahumada, M.; Jacques, E.; Calderon, C.; Martínez-Gómez, F. Porosity in biomaterials: A key factor in the development of applied materials in biomedicine. In Handbook of Ecomaterials; Martínez, L., Kharissova, O., Kharisov, B., Eds.; Springer: Cham, Switzerland, 2019; Volume 5, pp. 3503-3522. ISBN 9783319682556.

63. Sultana, N.; Hassan, M.I.; Lim, M.M. Fabrication and Characterization of Polymer and Composite Scaffolds Using Freeze-Drying Technique. In Composite Synthetic Scaffolds for Tissue Engineering and Regenerative Medicine; Springer: Cham, Switzerland, 2015; pp. 45-60. ISBN 9783319097558.

64. Othman, N.; Harruddin, N.; Idris, A.; Ooi, Z.Y.; Fatiha, N.; Raja Sulaiman, R.N. Fabrication of polypropylene membrane via thermally induced phase separation as a support matrix of tridodecylamine supported liquid membrane for Red 3BS dye removal. Desalin. Water Treat. 2016, 57, 12287-12301. [CrossRef]

65. Bahrami, N.; Farzin, A.; Bayat, F.; Goodarzi, A.; Salehi, M.; Karimi, R.; Mohamadnia, A.; Parhiz, A.; Ai, J. Optimization of 3D Alginate Scaffold Properties with Interconnected Porosity Using Freeze-drying Method for Cartilage Tissue Engineering Application. Arch. Neurosci. 2019, 6, 4-11. [CrossRef]

66. Tan, X.M.; Rodrigue, D. A review on porous polymeric membrane preparation. Part II: Production techniques with polyethylene, polydimethylsiloxane, polypropylene, polyimide, and polytetrafluoroethylene. Polymers 2019, 11, 1310. [CrossRef]

67. Zhang, X.; Huang, C.; Zhao, Y.; Jin, X. Preparation and characterization of nanoparticle reinforced alginate fibers with high porosity for potential wound dressing application. RSC Adv. 2017, 7, 39349-39358. [CrossRef]

68. KALTOSTAT®Calcium Sodium Alginate Dressing-Wound I ConvaTec. Available online: http:/ /www.convatec.com/products / pc-wound-alginate/kaltostat-calcium-sodium-alginate-dressing (accessed on 30 April 2021).

69. Ismail, N.M.; Jakariah, N.R.; Bolong, N.; Anissuzaman, S.M.; Nordin, N.A.H.M.; Razali, A.R. Effect of Polymer Concentration on the Morphology and Mechanical Properties of Asymmetric Polysulfone (PSf) Membrane. J. Appl. Membr. Sci. Technol. 2017, 21, 33-41. [CrossRef]

70. Shukla, S.; Favata, J.; Srivastava, V.; Shahbazmohamadi, S.; Tripathi, A.; Shukla, A. Effect of polymer and ion concentration on mechanical and drug release behavior of gellan hydrogels using factorial design. J. Polym. Sci. 2020, 58, 1365-1379. [CrossRef]

71. Rezvanian, M.; Ahmad, N.; Cairul, M.; Mohd, I.; Ng, S. Optimization, characterization, and in vitro assessment of alginate-pectin ionic cross-linked hydrogel film for wound dressing applications. Int. J. Biol. Macromol. 2017, 97, 131-140. [CrossRef]

72. Mohamad, N.; Mohd Amin, M.C.I.; Pandey, M.; Ahmad, N.; Rajab, N.F. Bacterial cellulose/acrylic acid hydrogel synthesized via electron beam irradiation: Accelerated burn wound healing in an animal model. Carbohydr. Polym. 2014, 114, 312-320. [CrossRef] 
73. Elsner, J.J.; Zilberman, M. Novel antibiotic-eluting wound dressings: An in vitro study and engineering aspects in the dressing's design. J. Tissue Viability 2010, 19, 54-66. [CrossRef] [PubMed]

74. Jadali, A.; Ghazizadeh, S. Protein kinase D is implicated in the reversible commitment to differentiation in primary cultures of mouse keratinocytes. J. Biol. Chem. 2010, 285, 23387-23397. [CrossRef]

75. Bikle, D.D.; Ng, D.; Tu, C.L.; Oda, Y.; Xie, Z. Calcium- and vitamin D-regulated keratinocyte differentiation. Mol. Cell. Endocrinol. 2001, 177, 161-171. [CrossRef]

76. Navarro-Requena, C.; Pérez-Amodio, S.; Castano, O.; Engel, E. Wound healing-promoting effects stimulated by extracellular calcium and calcium-releasing nanoparticles on dermal fibroblasts. Nanotechnology 2018, 29, 395102. [CrossRef]

77. Boateng, J.S.; Matthews, K.H.; Stevens, H.N.E.; Eccleston, G.M. Wound Healing Dressings and Drug Delivery Systems: A Review. J. Pharm. Sci. 2008, 97, 2892-2923. [CrossRef] 